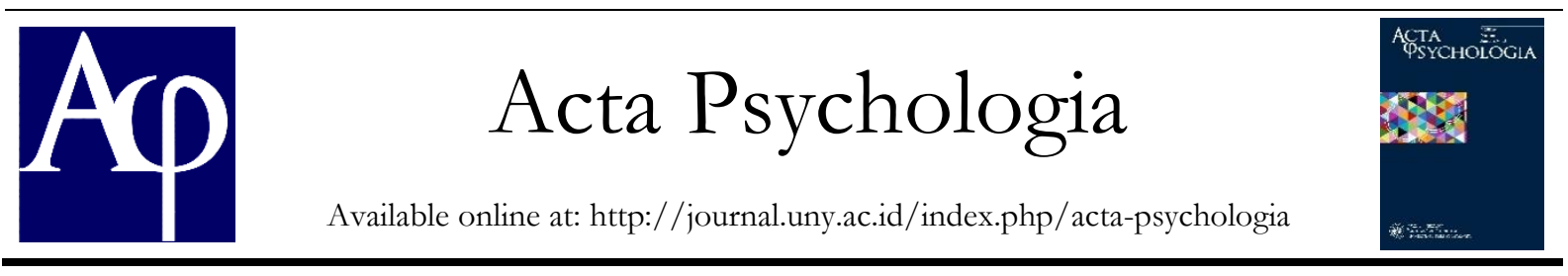

\title{
Pengaruh Kontrol Diri terhadap Intensitas Penggunaan Smartphone pada Remaja
}

\author{
Fernita Nurningtyas, Yulia Ayriza \\ Jurusan Psikologi, Fakultas Ilmu Pendidikan, Universitas Negeri Yogyakarta; \\ Jl. Colombo No. 1 Sleman Yogyakarta, 55281 \\ f.nurningtyas@yahoo.co.id
}

\begin{abstract}
Abstrak
Penelitian ini bertujuan untuk mengetahui pengaruh kontrol diri terhadap intensitas penggunaan smartphone pada remaja. Adapun pendekatan yang digunakan ialah pendekatan kuantitatif dengan jenis penelitian ex post facto. Penelitian ini dilakukan di Kota Yogyakarta dengan melibatkan 384 remaja berusia 15-18 tahun sebagai subjek. Pengambilan sampel dilakukan dengan menggunakan teknik incidental sampling dan data dikumpulkan dengan menggunakan kuisioner. Instrumen data yang digunakan adalah skala kontrol diri dan skala intensitas penggunaan smartphone. Validitas instrumen dilakukan dengan menilai validitas isi melalui expert judgment. Pengujian reliabilitas instrument dilakukan menggunakan alpha Cronbach dan menunjukkan nilai koefisien 0,908 pada skala kontrol diri. Teknik analisis data pada penelitian ini menggunakan regresi linear sederhana. Hasil penelitian menunjukkan bahwa terdapat pengaruh kontrol diri secara negatif dan signifikan terhadap intensitas penggunaan smartphone pada remaja usia 15-18 tahun di Kota Yogyakarta $(\beta=-0,102, \mathrm{p}<0,01)$ yang artinya kontrol diri mampu menjadi prediktor terhadap intensitas penggunaan smartphone.
\end{abstract}

Kata Kunci: kontrol diri, intensitas penggunaan smartphone, remaja

\begin{abstract}
This study aims to determine the effect of self-control on the intensity of smartphone use in adolescents. This research used a quantitative approach with ex post facto research. This research was conducted in Yogyakarta City involving 384 adolescents aged 15-18 years as research subjects. Sampling was done using incidental sampling technique and data were collected using a questionnaire. The instruments in this study were Self-Control Scale and The Intensity of Smartphone Use Scale. The content validity of the instrument is measured by expert judgment. Instrument reliability testing was carried out using Cronbach's alpha and showed a coefficient value of 0.908 on the Self-Control Scale. The data analysis technique used was simple linear regression. The results showed that there was a negative and significant effect of self-control on the intensity of smartphone use among adolescents aged 15-18 years in Yogyakarta City $(\beta=-0102, \mathrm{p}<0.05)$, means that self-control can be a predictor of the intensity of smartphone use.
\end{abstract}

Keywords: self-control, intensity of smartphone use, adolescents

\section{Pendahuluan}

Perkembangan teknologi dalam bidang komunikasi di Indonesia semakin pesat yang memberikan dampak positif dan negatif bagi setiap pengguna alat komunikasi. Salah satu hasil dari kemajuan teknologi dalam bidang komunikasi adalah semakin bertambahnya fitur-fitur yang diberikan oleh teknologi seperti smartphone. Smartphone adalah ponsel pintar yang menjadi media komunikasi praktis dan mudah digunakan yang saat ini sudah banyak digunakan oleh semua kalangan 
(Zulfitria, 2017). Adanya kemajuan zaman menuntut individu untuk selalu mengikuti perkembangan tersebut, agar selalu dapat mempermudah kehidupannya saat ini serta dapat menyesuaikan dengan orang-orang dan lingkungan sekitar yang semakin maju. Hal tersebut menjadi salah satu alasan mengenai penggunaan smartphone yang dibutuhkan semua kalangan dari anakanak hingga lansia. Alhady, Salsabila, dan Azizah (2018) menyebutkan bahwa dalam sebuah riset menunjukkan pengguna smartphone di Indonesia tahun 2018 sebanyak 83,18 juta orang, dimana jumlah tersebut berada diperingkat ketiga pengguna smartphone terbesar di Asia Pasifik. Berdasarkan hasil survey Kementerian Komunikasi dan Informatika yang didukung oleh UNICEF pada tahun 2014 menyebutkan bahwa remaja merupakan pengguna smartphone paling banyak yaitu sekitar $80 \%$ dari pengguna smartphone di Indonesia (Andriani, Sriati \& Yamin, 2019: 108).

Smartphone, termasuk barang mewah yang pasti dimiliki oleh kebanyakan orang. Dampak positif yang diperoleh dalam penggunaan smartphone adalah dapat mempermudah setiap kegiatan, namun disamping itu juga memberikan dampak negatif apabila penggunaannya tidak dikendalikan. Penggunaan smartphone dapat mempermudah mendapat berbagai informasi yang luas, serta dapat mempermudah komunikasi dengan orang lain. Dampak negatif yang dapat muncul pada penggunaan smartphone yang berlebihan, seperti dapat membuat individu menjadi kurang bersosialisasi, mengurangi konsentrasi, lupa waktu setiap menggunakannya, hingga dapat menyebabkan kecanduan (Yuni \& Pierewan 2017). Pada saat ini smartphone dibutuhkan oleh setiap penduduk di Indonesia dikarenakan dengan adanya dampak positif yang didapatkan dalam keterhubungan sosial dengan kerabat yang jauh, kemudahan dalam mengerjakan tugas, serta dapat menjadi hiburan bagi penggunanya, namun apabila penggunaan smartphone berlebihan, maka dapat memberikan dampak negatif bagi penggunanya yaitu berupa gangguan tidur, dan dapat mengganggu pekerjaan lain (Horwood \& Anglim, 2019). Waty dan Fourianalistyawati (2018) menyebutkan bahwa durasi ideal untuk penggunaan smartphone adalah 4 jam 17 menit dalam sehari.

Pengguna smartphone pada saat ini dapat menghabiskan waktunya untuk menggunakan fitur internet, dan media sosial (Nugraha, 2018). Menurut Wibawa dan Pradekso (2018) ketika individu merasa puas dan mendapatkan kesenangan dalam penggunaan fitur-fitur pada smartphone, maka dapat meningkatkan intensitas penggunaan smartphone. Penggunaan smartphone dengan bijak dan tidak melebihi batas waktu ideal penggunaannya, dapat mengurangi penggunaan smartphone yang berlebihan dan untuk hal yang kurang bermanfaat (Wilantika, 2017).

Intensitas penggunaan smartphone yang semakin meningkat dan tidak dikendalikan dapat menimbulkan kecanduan smartphone (Putra, 2015 dalam Adiani, Sriati, dan Yamin). Ameliola \& Nugraha (2013) (dalam Mulyati \& NRH 2018) menyebutkan bahwa semakin meningkatnya intensitas penggunaan smartphone pada remaja akan menimbulkan beberapa permasalahan seperti kurang memperhatikan dan acuh tak acuh pada lingkungan sosial, kurang bersosialisasi, rasa saling menghargai sesama menjadi berkurang. Dalam hal ini, maka dibutuhkan kontrol diri dari remaja untuk dapat mengurangi intensitas penggunaan smartphone.

Kontrol diri adalah kemampuan individu untuk menyusun, membimbing, mengatur, dan mengarahkan perilaku yang membawa individu kearah yang lebih baik (Goldfried \& Merbaum, dalam Ghufron \& 
Risnawati, 2014). Kontrol diri dapat membuat individu mengurangi masalah perilaku dan akan lebih dipercaya oleh orang lain (Baumiester, 2018). Menurut Skinner (dalam Hirt, 2016) kontrol diri lebih berfokus pada modifikasi perilaku untuk dapat mengendalikan tindakan dan lingkungan untuk menghindari keinginan kita.

Kontrol diri merupakan salah satu dari tiga aspek yang disebutkan dalam faktor internal yang dapat mengurangi resiko kecanduan smartphone pada individu. Individu diharapkan dapat memiliki kontrol diri yang baik, sehingga individu tersebut dapat mengatur intensitas penggunaan smartphone agar nantinya tidak menimbulkan masalah bagi diri sendiri maupun orang lain di sekitar. Kontrol diri yang baik dapat membuat individu mengurangi waktu penggunaan smartphone (Agusta, 2016).

Dalam penelitian Youarti dan Hidayah (2018) yang membahas mengenai perilaku phubbing sebagai karakter generasi $\mathrm{Z}$ menyebutkan bahwa, remaja yang termasuk dalam generasi $\mathrm{z}$ sebagai pengguna smartphone, akan merasa mendapat kepuasan dan kemudahan dari kemajuan teknologi dalam bidang komunikasi tersebut. Kepuasan dan kemudahan dari smartphone membuat remaja menjadi berkali-kali mengeceknya. Remaja tersebut akan melakukan tindakan menyakiti lawan bicaranya karena terlalu asik dengan smartphonenya hingga mengabaikan lawan bicaranya. Berkaitan dengan subjek penelitian ini, maka seorang remaja hendaknya dapat memiliki keterampilan untuk dapat mengendalikan perilakunya agar terhindar dari perilaku yang menyimpang. Kontrol diri dikatakan sebagai ketrampilan mengendalikan perilaku agar dapat menyesuaikan dengan nilai dan norma yang ada di masyarakat (Andriani, Sriyati, dan Yamin, 2019).
Penelitian dilakukan karena pada saat ini tingkat serta intensitas penggunaan smartphone semakin meningkat serta penggunaannya yang belum dapat dikenadalikan oleh pengguna smartphone terutama pada kalangan remaja, sehingga diperlukan kontrol diri untuk dapat mengendalikan intensitas penggunaan smartphone.

\section{Metode Penelitian}

\section{Jenis Penelitian}

Pendekatan penelitian yang digunakan dalam penelitian ini adalah dengan penelitian kuantitatif. Penelitian kuantitatif merupakan penelitian yang dilakukan dengan analisis data untuk menguji hipotesis sehingga dapat menjawab masalah (Purwanto, 2008). Jenis penelitian yang digunakan adalah penelitian ex post facto. Sugiyono (2017) menyebutkan bahwa penelitian ex post facto digunakan untuk meneliti peristiwa yang telah terjadi dan mengetahui faktor-faktor yang menimbulkan kejadian tersebut. Menurut Creswell (2010) penelitian kuantitatif merupakan penelitian yang menguji teoriteori tertentu dengan meneliti hubungan antar variabel, dimana variabel-variabel dalam penelitian kuantitatif diukur dengan instrumen-instrumen, sehingga diperoleh data berupa angka dan dianalisis berdasar prosedur statistik.

\section{Waktu dan Tempat Penelitian}

Penelitian mengenai kontrol diri dan intensitas penggunaan smartphone pada remaja tengah, yang akan dilakukan di Kota Yogyakarta. Penelitian ini dilakukan pada 19 September 2019 - 31 Juli 2020.

\section{Subjek Penelitian}

Subjek pada penelitian ini adalah remaja yang berusia 15-18 tahun sebanyak 384 orang. Kriteria sunjek adalah remaja berusia 15-18 tahun, berdomisili di Kota Yogyakarta, dan memiliki smartphone.

Penentuan jumlah sampel pada penelitian 
ini adalah dengan menggunakan rumus Krejie dan Morgan. Hasil perhitungan dengan rumus Krejie dan Morgan didapatkan sejumlah 380 sampel penelitian. Teknik pengambilan sampel pada penelitian ini menggunakan incidental sampling, yaitu sampel yang diperoleh dari subjek yang dijumpai (Setiawati, 2017).

\section{Teknik dan Instrumen Pengumpulan Data}

Teknik pengumpulan data yang digunakan adalah dengan kuisioner, dimana kuisioner berisi pernyataan mengenai kontrol diri pada penggunaan smartphone dan intensitas penggunaan smartphone. Kuisioner dan isian singkat dibuat sendiri oleh peneliti untuk mengukur variabel penelitian. Skala yang digunakan pada instrumen kontrol diri pada penggunaan smartphone adalah dengan modifikasi skala Likert. Penelitian ini menggunakan empat pilihan jawaban pada instrumen kontrol diri yaitu Sangat Tidak Sesuai bernilai 1, Tidak Sesuai bernilai 2, Sesuai bernilai 3, Sangat Sesuai bernilai 4. Penelitian dilakukan dengan menyebar kuisioner online pada remaja berusia 15-18 tahun di Kota Yogyakarta.

\section{Teknik Analisis Data}

Teknik analisis data yang digunakan dalam penelitian ini adalah analisis deskriptif, uji prasyarat analisis dan uji hipotesis. Analisis deskriptif bertujuan untuk memberikan deskripsi mengenai data dari variabel yang diperoleh melalui kelompok subjek penelitian dan tidak dimaksudkan untuk pengujian hipotesis (Azwar, 2017). Uji prasyarat analisis meliputi uji normalitas dan uji linearitas yang dihitung dengan bantuan program SPSS. Uji hipotesis yang digunakan pada penelitian ini adalah dengan analisis regresi sederhana. Uji hipotesis bertujuan untuk memprediksi suatu gejala pada satu variabel terhadap variabel lain (Setiawati, 2017).

\section{Hasil Penelitian dan Pembahasan}

\section{Deskripsi Subjek Penelitian}

Berdasarkan hasil analisis deskriptif pada 382 remaja berusia 15-18 di Kota Yogyakarta. Dari jumlah keseluruhan responden, karakteristik responden berdasar usia, dapat dilihat melalui tabel berikut:

Tabel 1. Deskripsi Usia Subjek

\begin{tabular}{lcl}
\hline Rentang Usia & Jumlah & Total \\
\hline 15 tahun & 95 & 382 \\
16 tahun & 133 & \\
17 tahun & 107 & \\
18 tahun & 49 & \\
\hline
\end{tabular}

\section{Deskripsi Data}

Berdasarkan hasil analisis deskriptif kategorisasi pada masing-masing variabel, maka diperoleh data sebagai berikut (gambar grafik dapat dilihat pada gambar 1 dan gambar 2).

Mean ideal pada data statistik variabel kontrol diri adalah 52,5. Standar deviasi pada variabel kontrol diri adalah 10,50. Kategorisasi kontrol diri pada subjek penelitian terlihat diagram distribusi frekuensi sebagai berikut:

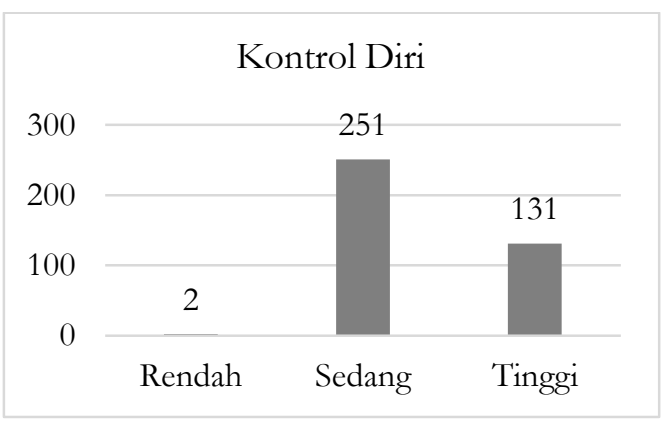

Gambar 1. Diagram Kategori Kontrol Diri

Gambar 1 menunjukkan jumlah remaja yang dengan kontrol diri pada tingkat rendah sebanyak 2 orang, remaja dengan kontrol diri sedang sebanyak 251orang, dan kontrol diri tinggi sebanyak 131 orang. Subjek paling banyak berada dalam kontrol diri dalam tingkat sedang. 
Pada variabel intensitas penggunaan smartphone pada menunjukkan mean ideal sebesar 5, sedangkan standar deviasi menunjukkan nilai 1, maka didapatkan kategorisasi sebagai berikut:

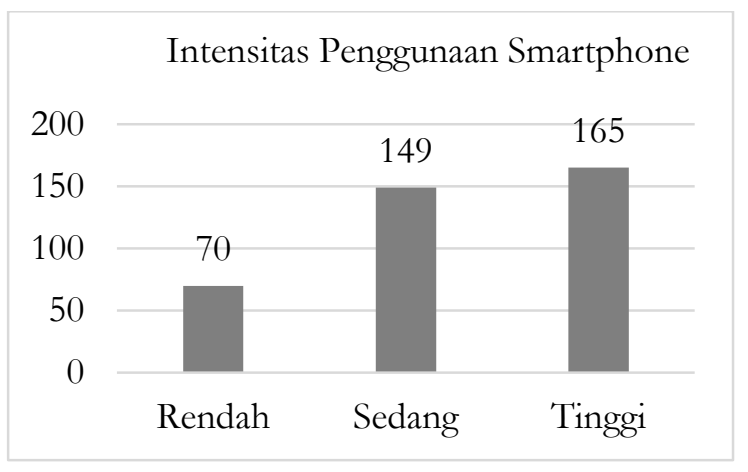

Gambar 2. Kategorisasi Intensitas

Penggunaan Smartphone

Gambar 2 menunjukkan bahwa subjek yang memiliki intensitas peggunaan smartphone yang rendah sebanyak 70 orang, intensitas smartphone sedang sebanyak 149 orang, dan intenssitas penggunaan smartphone tinggi sebanyak 165. Subyek didominasi dengan intensitas penggunaan smartphone yang tinggi.

Hasil uji hipotesis dalam penelitian ini menunjukkan bahwa terdapat pengaruh negatif kontrol diri terhadap intensitas penggunaan smartphone pada remaja berusia 15-18 tahun di Kota Yogyakarta. Hasil tersebut sesuai dengan hipotesis pada penelitian ini. Hal ini dapat dilihat dari koefisien pada analisis regresi sederhana sebesar -0,102 ( $\mathrm{p}<0,01)$. Koefisien bernilai negatif, yang menunjukkan bahwa pada setiap penambahan skor 1 pada variabel kontrol diri, maka intensitas penggunaan smartphone berkurang $0,102(\mathrm{p}<0,01)$

Hasil tersebut didukung oleh penelitian Karuniawan dan Cahyati (2013) dalam Asih, dan Fauziah (2017) yang menyatakan bahwa kontrol diri memiliki peran dalam mengontrol penggunaan smartphone yang berlebihan. Penelitian Agusta (2016) mengenai Faktor-Faktor Resiko Kecanduan Menggunakan Smartphone Pada
Siswa SMK Negeri 1 Kalasan Yogyakarta menyebutkan bahwa kontrol diri yang rendah merupakan aspek yang paling mempengaruhi kecanduan smartphone. Variabel lain yang menjelaskan intensitas penggunaan smartphone dan tidak diteliti dalam penelitian ini adalah faktor situasional, faktor eksternal, dan faktor sosial. Hasil penelitian ini menyebutkan bahwa kontrol diri sebagian besar pada tingkat sedang, namun dengan intensitas penggunaan smartphone yang tinggi dikarenakan adanya faktor dari luar diri subjek. Hal tersebut menyebabkan intensitas penggunaan smartphone pada subjek penelitian didominasi dengan tingginya intensitas penggunaan smartphone.

Pada penelitian ini, subjek memiliki pengendalian diri dalam tingkat sedang, dimana subjek belum sepenuhnya dapat mengendalikan diri dalam penggunaan smartphone, sehingga meningkatkan intensitas penggunaan smartphone, selain itu terdapat faktor eksternal yang membuat intensitas penggunaan smartphone menjadi tinggi.

\section{Simpulan dan Saran}

\section{Simpulan}

Berdasarkan analisis deskripsi pada masing-masing variabel, diperoleh hasil bahwa subjek yaitu remaja berusia 15-18 tahun di Kota Yogyakarta sebagian besar memiliki kontrol diri dalam tingkat sedang dengan intensitas penggunaan smartphone yang tinggi. Penggunaan smartphone pada subjek paling banyak didominasi pada penggunaan sosial media seperti WhatsApp, instagram, dan lainnya.

Hasil penelitian ini menyebutkan bahwa kontrol diri berpengaruh negatif secara signifikan terhadap intensitas penggunaan smartphone pada subjek. Kontrol diri dapat menjadi prediktor bagi intensitas penggunaan smartphone. kontrol diri menjelaskan varians intensitas penggunaan smartphone sebesar $16,9 \%$ dan 
sisanya sebesar 83,1\% dijelaskan oleh variabel lain yang tidak diteliti.

Saran

Berdasarkan hasil penelitian ini, maka saran bagi remaja, hendaknya dapat meningkatkan kontrol diri sehingga intensitas penggunaan smartphone menurun. Peningkatan kontrol diri dapat dilakukan dengan mengatur stimulusnya. Individu hendaknya dapat mengetahui kapan dan bagaimana stimulus yang dapat meningkatkan intensitas pnggunaan smartphone itu muncul, sehingga dapat mengantisipasi munculnya penyebab intensitas penggunaan smartphone menjadi tinggi. Hal tersebut dapat membuat individu dapat mengendalikan diri dari penggunaan smartphone yang berlebihan dan hal yang kurang bermanfaat.

Saran bagi peneliti selanjutnya, diharapkan dapat melakukan penelitian pada remaja dengan rentang usia yang lebih luas agar dapat mengetahui kontrol diri pada semua rentang usia remaja.

\section{Daftar Pustaka}

Agusta, Duha. (2016). Faktor-faktor resiko kecanduan menggunakan smartphone pada siswa di Smk Negeri 1 Kalasan Yogyakarta. EJornal Bimbingan Dan Konseling Edisi 3 Tabun Ke-5.

Asih, A. T., \& Fauziah, N. (2017). Hubungan antara kontrol diri dengan kecemasan jauh dari smartphone (nomophobia) pada mahasiswa jurusan ilmu komunikasi fakultas ilmu sosial dan politik Universitas Diponegoro Semarang. Jurnal Empati, 6 (2).

Azwar, Saifuddin. 2017. Metode penelitian psikologi. Yogyakarta: Pustaka Pelajar

Baumeister, R. F. (2018). Self-regulation and self-control. New York: Routledge.
Creswell, J. W. 2010. Research Design: pendekatan kualitatif, kuantitatif, dan mixed. Yogyakarta: PT.Pustaka Pelajar.

Ghufron \& Rini. (2014). Teori-teori psikologi. Yogyakarta: Ar Ruzz Media

Hirt, dkk. (2016). Self-Regulation And Ego Control. United Kingdom: Elsevier

Horwood \& Anglim. (2019). Problematic smartphone usage and subjective and psychological well-being. Journal Computers in Human Behavior. 97, 44-50.

Purwanto. 2008. Metodologi penelitian kuantitatif. Yogyakarta: Pustaka Pelajar

Setiawati, F.A. (2017). Statistika Terapan: Untuk Penelitian Pendidikan dan Sosial. Yogyakarta: Parama

Sugiyono (2010) Metode penelitian kuantitatif kualitatif dan R\&D. Bandung: Alfabeta.

Waty, L.P. \& Fourianalistyawati, E. (2018). Dinamika kecanduan telepon pintar (Smartphone) pada remaja dan trait mindfulness sebagai alternatif solusi. Jurnal Psikologi Unsyiah, (1)2.

Wilantika, C.F. (2017). Pengaruh pengguaan smartphone terhadap kesehatan dan perilaku remaja. Akademi Kebidanan La Tansa Mashiro.

Yuni, R.S.P., \& Pierawan, A.C. (2017). Hubungan intensitas penggunaan smartphone dengan disiplin belajar siswa. Universitas Negeri Yogyakarta.

Youarti, I.E \& Hidayah, Nur. (2018). Perilaku phubbing sebagai karakter remaja generasi z. Jurnal Fokus Konsesing, 4 
Zulfitria (2017). Pola asuh orang tua dalam penggunaan smartphone pada anak sekolah dasar. Jurnal ilmiah PGSD 1(2). 